\title{
A Murder Committed by an Insidious and Cruel Killer: Hypertension and Heart
}

\author{
Bilgin Bahadır BasgozZ ${ }^{1 *}$, Adem Aydin², Ilker Tasci ${ }^{3}$ and Kenan Saglam² \\ ${ }^{1}$ Department of Internal Medicine, Gulhane Research and Training Hospital, Turkey \\ ${ }^{2}$ Department of Internal Medicine, Health Sciences University, Turkey \\ ${ }^{3}$ Department of Geriatrics, Health Sciences University, Turkey
}

Submission: December 18, 2017; Published: January 17, 2018

*Corresponding author: Bilgin Bahadır Basgoz, Department of Internal Medicine, Gulhane Research and Training Hospital, Turkey,

Email: bbbasgoz@gmail.com

Abstract

Hypertension is one the major preventable causes of death and morbidity. The prevalence of hypertension is approximately $30-35 \%$ at studies conducted in countries. Today; the role played by hypertension in the development of heart failure and coronary heart disease and the benefits of primary prevention with effective treatment have been clearly demonstrated. The significance of treatment of hypertension in terms of secondary prevention has also been established in patients with heart failure and coronary heart disease. By the current guidelines, hypertension treatment goals has been individualized and specific patient groups have also been amide to provide the highest benefit from therapy. Early identification and effective treatment of hypertension therefore has vital importance for both primary and secondary prevention.

Keywords: Hypertension; Coronary artery disease; Heart failure; Primary prevention

\section{Introduction}

Hypertension is one the major preventable causes of death and morbidity. According to JNC 7 report; patients under antihypertensive treatment and/or patients with systolic blood pressure (SBP) $\geq 140 \mathrm{mmHg}$ or diastolic blood pressure (DBP) $\geq 90 \mathrm{mmHg}$ are defined as hypertensive [1]. The definitions of prehypertension and hypertension, defined by the JNC 7, are not repeated in the current JNC 8 commission report. The treatment goals and threshold values based on age and comorbidities are determined instead [2]. In this way, individualization of definitions and targets are ensured.

Blood pressure values vary depending on age. While in young hypertensive subjects, DBP is proment; elevated SBP, or even elevated SBP alone (isolated systolic hypertension) group is the predominant form of hypertension in the elderly patients [3].

\section{Epidemiology}

The most comprehensive study to determine the frequency of hypertension in our country, Patent (Prevalence, Awareness, Treatment and Control of Hypertension in Turkey) was held in 2003 with 4910 participants. According to the data obtained from this study, hypertension prevalence in our country was $31.8 \%$ and was higher in females than in males $(31.6 \%-27.5 \%$, p $>0.001)$ [4].
The same study found that $40.7 \%$ of those with hypertension were aware of their illness, only $31.1 \%$ of them were using treatment and only $8.1 \%$ of have blood pressure values in the target range [4].

With the aim of determining whether there is a change in the prevalence of hypertension and patients under control also awareness within the next 10 years, The Patent 2 study was conducted in 2012 with 5437 participants and the prevalence of hypertension was found to be $30.3 \%$. (32.3\% in females and $28.4 \%$ in males, $\mathrm{p}=0.002$ ) [5]. However, the prevalence of hypertension awareness, the drug use proportion and the frequency of blood pressure values in the target range was found $54.7 \%, 47.4 \%$ and $28.7 \%$ respectively [5]. As a result, there was no change in the prevalence of hypertension in Turkey within 10 years $(31.8 \%$ and $30.3 \%, \mathrm{p}=0.123)$; but the awareness, $(40.7 \%$ ve $54 \%, 7, \mathrm{p}$ $<0,001)$ the drug use proportion $(31.1 \%$ ve $47 \%, 4, p<0.001)$ and the frequency of blood pressure values in the target range $(8.1 \%$ ve $\% 28.7 \mathrm{p}<0.001$ ) increased significantly [5].

Hypertension and Congestive Heart Failure the Effects on Development

Today, structural ventricular changes caused by chronic hypertension and subsequent systolic and diastolic ventricular 
dysfunction are well known [6]. The heart works against the peripheral vascular resistance and the after load created by large and medium arteriosclerotic stiffness. Therefore; the increased blood pressure increases the hemodynamic load of the heart muscle, and consequently the cardiac muscle mass increases as a consequence of the compensatory mechanisms to provide normal cardiac output $[7,8]$. After all; hypertrophy of the left ventricle in the pre-hypertensive and hypertensive patients is slow but continuous $[9,10]$. This initially restricts the ability of the heart to relax and fill during rest and then during the exercise as time progresses $[11,12]$. This condition, which is secondary to hypertension and is defined as ventricular diastolic dysfunction, appears to be an important factor in the progression of overt heart failure. In addition to this, , the disproportionately increased left ventricle muscle as consequence of hypertension results in chronic subendocardial hypoperfusion, both at rest and during exercise, since the microvascular circulation required to feed the hypertrophied heart will be insufficient [13].

In addition to chronic hypertension, acute hypertensive crises can also lead to heart failure (HF). Sudden elevations in blood pressure (e.g., hypertensive emergency); has been shown to cause $\mathrm{HF}$ and acute pulmonary edema by causing worsening of diastolic dysfunction without a decrease in the ejection fraction (temporary systolic dysfunction) or mitral insufficiency [14].

\section{Epidemiology of Heart Failure and Hypertension}

In the Framingham study, 5143 patients without KY were followed for a mean of 14.1 years and 392 new diagnoses were identified [6]. In 357(91\%) of these cases, hypertension was detected before development of HF. Regression analysis of patients with normal blood pressure revealed that the risk of developing HF in hypertension patients was 2 times higher in men than in those with normal blood pressure and 3 times higher in women [6]. This suggests that the most common risk factor for $\mathrm{HF}$ is hypertension.

\section{The Effects of Hypertension Therapy on HF}

Effective treatment of patients with hypertension has been shown to be beneficial in preventing and treatment of heart failure through many other clinical trials. In the treatment group, the incidence of HF development was significantly lower than the placebo group (RR, 0.51; 95\% [CI], 0.37-0.71; P <0.001) [15]. According to the same study, it was determined that a new HF case could be prevented if 48 patients with hypertension were treated effectively (NNT:48) [15]. In another primer prevention trial, similarly, it has been shown that treating patients with hypertension with blood pressure lowering agents can reduce the incidence of $\mathrm{HF}$ by up to $50 \%$ [16]. A significant reduction both the incidence of new cardiovascular events and the incidence of progression to HF have been shown in patients with cardiovascular disease if treated effectively in accordance with blood pressure targets specified by JNC [17]. Studies in patients with hypertension with left ventricular systolic dysfunction or left ventricular hypertrophy have also found that ventricular remodeling is prevented or delayed as well as the incidence of overt CHD is reduced if the blood pressure control is provided $[18,19]$. It has been shown that blood pressure lowering therapy is effective in protecting against $\mathrm{HF}$ and also has a positive effect on decreasing the mortality rate, slowing the progress of the disease, decreasing the frequency and duration of hospital admission, increasing the quality of life and functional capacity by effective blood pressure control even if the patient has developed HF [20].

In conclusion, the epidemiological and clinical studies summarized above provide a critical role of hypertension in the development of HF. In middle-aged women and men who have not yet been diagnosed with hypertension, the risk of developing hypertension for the rest of their lives is estimated at 90\% [21].

\section{Hypertension and Coronary Artery Disease the Effects on Development}

Hypertension causes the formation of left ventricular hypertrophy with the mechanisms we specify in the HF section $[7,10]$. In the presence of hypertension and hypertrophy, there is an increase in myocardial oxygen demand due to increased heart workload. However, in the presence of concentric hypertrophy, myocardial ischemia is observed because the oxygen requirement cannot be fully met by increasing the subendocardial blood flow [22]. Experimental studies revealed subendo cardial ischemia during exercise and pacemaker-induced tachycardia in cardiac hypertrophy even if there is no coronary artery disease (CAD) $[23,24]$. Also, 2 to 5 -fold increased myocardial infarction (MI) incidence was shown in the long-term follow-up of patients with left ventricular hypertrophy by Vasan et al. [16]. Hypertension, in addition, causes rupture of unstable plaques through endothelial shear stress and can trigger acute coronary syndromes [25].

\section{Epidemiology of CAD and Hypertension}

Epidemiological studies show a strong association between hypertension and CAD, and hypertension is considered as an independent major risk factor for all age, gender and ethnic groups in terms of CAD [3]. Such that an increase in blood pressure causes an increase in the risk of CAD almost linearly, to begin with values not yet defined as hypertension (Systolic $>120 \mathrm{mmHg}$, Diastolic $>80 \mathrm{mmHg}$ ) [26]. However, the significance of SBP and DBP as a risk factor varies according to age groups. SBP is the main determinant of CAD risk in patients under 50 years of age, whereas SBP is more important in patients over 60 years of age [27]. Through the same study it was determined that the strongest risk factor for CAD in patients aged 60 years and older was the pulse pressure (the difference between SBP and DBP). In addition, it should be emphasized that DBP is inversely proportional to the risk of CAD in this age group [27]. According to the results of a meta-analysis involving a total of 61 studies with approximately one million adults, each increase of $20 \mathrm{mmHg}$ in SBP and $10 \mathrm{mmHg}$ in DBP-from $150 / 75 \mathrm{mmHg}$ to $185 / 115 \mathrm{mmHg}$ - doubles the risk of lethal coronary events [28]. Besides, the risk of lethal coronary 
event rate in patients aged 80-89 years is about 16 times higher than that of 40-49 years old patients with the same SBP values [29]. Finally, it is predicted that lower blood pressure values are associated with lower disease risk and that effective blood pressure control can prevent future coronary events [29].

\section{The Effects of Hypertension Therapy on CAD}

Today, with effective antihypertensive therapy, it is known that there is a significant reduction in the risk of CAD and associated mortality and morbidity. In a study review the results of 6 placebo-controlled clinical trials, ACE inhibitor use reduced $20 \%$ (95\% CI 11-28) in CAD and 21\% (95\% CI 14-27) in major cardiovascular events compared with placebo, the use of channel blockers reduced the incidence of major cardiovascular events by $28 \%$ (95\% CI 13-41) compared to placebo [30]. Another study found that a reduction of $10 \mathrm{mmHg}$ in SBP or $5 \mathrm{mmHg}$ in DBP, in the middle age group, reduced the risk of death due to CAD and other vascular causes by approximately $40-50 \%$, in elderly patients, this benefit has been shown to continue with decreasing [28]. Nevertheless, in a study of 571 patients in the very advanced age group ( $>85$ years), a mean follow-up of 4.2 years showed that cardiovascular mortality increased in those with the history of hypertension; [relative risk (RR) 1.60, CI 1,06-2,40] however there was no significant difference in the frequency of mortality due to all causes [RR 1,19, CI 0,91-1,55] [31]. In other words, regardless of the history of hypertension, there was no negative effect on the mortality rate of high blood pressure in a very advanced age group. On the other hand, values below $140 / 70 \mathrm{mmHg}$ were found to be an effect of increasing the mortality rate for this age group [31]. Similarly, in another placebo-controlled study with 3845 patients over 80 years of age, reduction in blood pressure resulted in a significant decrease of $39 \%(95 \% \mathrm{CI}, 1-62 ; \mathrm{P}=0.05)$ and $64 \%$ (95\% CI, 42-78; P <0.001), respectively, in the fatal stroke and the frequency of heart failure but despite a decrease in the frequency of cardiovascular deaths by $23 \%$ (95\% CI, $-1-40$; P = 0.06), it did not reach statistical significance [32].

In patients with CAD or high risk of CAD development; there are many studies showing positive effects of ACE inhibitor use on CAD endpoints in both hypertensive and non-hypertensive groups $[17,33,34]$. However, although the risk of CAD was demonstrated higher in the prehypertensive patients than in the optimal blood pressure group; there has not yet been a clinical trial designed to suggest that treatment of this group would provide additional benefit $[26,28]$. Prehypertensive individuals were included in the study of TROPHY, the only prospective clinical trial for lowering blood pressure in individuals with normal blood pressure, and were treated with candesartan placebo-controlled for 2 years followed by an additional 2 years without any therapy [35]. At the end of the 4 th year, the development of hypertension was significantly lower in the group using candesartan and the relative risk reduction was determined as $66.3 \%(p<0,001)$ and $15.6 \%$ ( $\mathrm{p}<0.007$ ) in the candesartan group at the 2 nd year and 4 th year respectively. However, the study was not designed to evaluate the
CAD and related endpoints, so does not provide information on this subject.

\section{Conclusion}

Hypertension is an independent major risk factor in terms of CAD and HF. Obesity, sedentary lifestyle, prepared food consumption brought by the new age as well as additional risk factors such as increased sodium consumption ,stress and prolonged life expectancy has resulted in increase the prevalence of disease. In addition, the increased awareness of the patients and the facilitation of access to healthcare providers have made it possible for more patients to be diagnosed. In primary prevention, if the patient is effectively treated for delivery to the blood pressure targets stated by the guidelines the destructive effects of the disease on the heart can be prevented.

\section{References}

1. Chobanian AV, Bakris GL, Black HR, Cushman WC, Green LA, et al. (2003) The seventh report of the joint national committee on prevention, detection, evaluation, and treatment of high blood pressure: The JNC 7 report Jama 289(19): 2560-2572.

2. James PA, Oparil S, Carter BL, Cushman WC, Dennison-Himmelfarb C, et al. (2014) Evidence-based guideline for the management of high blood pressure in adults: report from the panel members appointed to the Eighth Joint National Committee (JNC 8). Jama 311(5): 507-520.

3. Rosendorff C, Lackland DT, Allison M, Aronow WS, Black HR, et al. (2015) Treatment of hypertension in patients with coronary artery disease: a scientific statement from the American Heart Association, American College of Cardiology, and American Society of Hypertension. J Am Soc Hypertens 65(6): 1372-1407.

4. Altun B, Arici M, Nergizoğlu G, Derici U, Karatan O, et al. (2005) Prevalence, awareness, treatment and control of hypertension in Turkey (the Patent study) in 2003. J Hypertens 23(10): 1817-1823.

5. Sengul S, Akpolat T, Erdem Y, Derici U, Arici M, et al. (2016) Changes in hypertension prevalence, awareness, treatment, and control rates in Turkey from 2003 to 2012. J Hypertens 34(6): 1208-1217.

6. Levy D, Larson MG, Vasan RS, Kannel WB, Ho KK (1996) The progression from hypertension to congestive heart failure. Jama 275(20): 1557-1562.

7. Kannel WB, Dannenberg AL, Levy D (1987) Population implications of electrocardiographic left ventricular hypertrophy. Am J Cardiol 60(17): 85i-93i.

8. Kannel WB, Gordon T, Offutt D (1969) Left ventricular hypertrophy by electrocardiogram. Prevalence, incidence, and mortality in the Framingham study. Ann Intern Med 71(1): 89-105.

9. Levy D, Anderson KM, Savage DD, Kannel WB, Christiansen JC, et al. (1988) Echocardiographically detected left ventricular hypertrophy: prevalence and risk factors. The Framingham Heart Study. Ann Intern Med 108(1): 7-13.

10. Urbina EM, Gidding SS, Bao W, Pickoff AS, Berdusis K, et al. (1995) Effect of body size, ponderosity, and blood pressure on left ventricular growth in children and young adults in the Bogalusa Heart Study. Circulation 91(9): 2400-2406.

11. Inouye I, Massie B, Loge D, Topic N, Silverstein D, et al. (1984) Abnormal left ventricular filling: an early finding in mild to moderate systemic hypertension. Am J Cardiol 53(1): 120-126.

12. Smith VE, Schulman P, Karimeddini MK, White WB, Meeran MK, et 
al. (1985) Rapid ventricular filling in left ventricular hypertrophy: II. Pathologic hypertrophy. J Am Coll Cardiol 5(4): 869-874.

13. Marcus ML, Harrison DG, Chilian WM, Koyanagi S, Inou T, et al. (1987) Alterations in the coronary circulation in hypertrophied ventricles. Circulation 75(1 Pt 2): 119-125.

14. Gandhi SK, Powers JC, Nomeir AM, Fowle K, Kitzman DW, et al. (2001) The pathogenesis of acute pulmonary edema associated with hypertension. N Engl J Med 344(1): 17-22.

15. Kostis JB, Davis BR, Cutler J, Grimm RH, Berge KG, et al. (1997) Prevention of heart failure by antihypertensive drug treatment in older persons with isolated systolic hypertension. SHEP Cooperative Research Group. Jama 278(3): 212-216.

16. Vasan RS, Levy D (1996) The role of hypertension in the pathogenesis of heart failure. A clinical mechanistic overview. Arch Intern Med 156(16): 1789-1796.

17. Yusuf S, Sleight P, Pogue J, Bosch J, Davies R, et al. (2000) Effects of an angiotensin-converting-enzyme inhibitor, ramipril, on cardiovascular events in high-risk patients. N Engl J Med 342(3): 145-153.

18. Yusuf S, Pitt B, Davis CE, Hood WB, Cohn JN (1992) Effect of enalapril on mortality and the development of heart failure in asymptomatic patients with reduced left ventricular ejection fractions. N Engl J Med 327(10): 685-691.

19. Mathew J, Sleight P, Lonn E, Johnstone D, Pogue J, et al. (2001) Reduction of cardiovascular risk by regression of electrocardiographic markers of left ventricular hypertrophy by the angiotensin-converting enzyme inhibitor ramipril. Circulation 104(14): 1615-1621.

20. Packer M, Coats AJ, Fowler MB, Katus HA, Krum H, et al. (2001) Effect of carvedilol on survival in severe chronic heart failure. N Engl J Med 344(22): 1651-1658.

21. Vasan RS, Beiser A, Seshadri S, Larson MG, Kannel WB, et al. (2002) Residual lifetime risk for developing hypertension in middle-aged women and men: The Framingham heart study. Jama 287(8): 10031010 .

22. Brush JE, Cannon RO, Schenke WH, Bonow RO, Leon MB, et al. (1988) Angina due to coronary microvascular disease in hypertensive patients without left ventricular hypertrophy. $\mathrm{N} \mathrm{Engl} \mathrm{J}$ Med 319(20): 1302-1307.

23. Bache RJ, Arentzen CE, Simon AB, Vrobel TR (1984) Abnormalities in myocardial perfusion during tachycardia in dogs with left ventricular hypertrophy: metabolic evidence for myocardial ischemia. Circulation 69(2): 409-417.
24. Zhang J, Merkle H, Hendrich K, Garwood M, From AH, et al. (1993) Bioenergetic abnormalities associated with severe left ventricular hypertrophy. J Clin Invest 92(2): 993-1003.

25. Falk, E, Shah PK, Fuster V (1995) Coronary plaque disruption. Circulation 92(3): 657-671.

26. Stamler J, Stamler R, Neaton JD (1993) Neaton, Blood pressure, systolic and diastolic, and cardiovascular risks. US population data. Arch Intern Med 153(5): 598-615.

27. Franklin SS, Larson MG, Khan SA, Wong ND, Leip EP, et al. (2001) Does the relation of blood pressure to coronary heart disease risk change with aging? The Framingham Heart Study. Circulation 103(9): 1245-1249.

28. Lewington S, Clarke R, Qizilbash N, Peto R, Collins R (2002) Agespecific relevance of usual blood pressure to vascular mortality: a meta-analysis of individual data for one million adults in 61 prospective studies. Lancet 360(9349): 1903-1913.

29. Yusuf S (2006) Preventing vascular events due to elevated blood pressure. Circulation 113(18): 2166-2168.

30. Neal B, Mac Mahon S, Chapman N (2000) Effects of ACE inhibitors, calcium antagonists, and other blood-pressure-lowering drugs: results of prospectively designed overviews of randomised trials. Blood pressure lowering treatment Trialists' collaboration. Lancet 356(9246): 1955-1964.

31. van Bemmel T, Gussekloo J, Westendorp RG, Blauw GJ (2006) In a population-based prospective study, no association between high blood pressure and mortality after age 85 years. J Hypertens 24(2): 287-292.

32. Beckett NS (2008) Treatment of hypertension in patients 80 years of age or older. N Engl J Med 358(18): 1887-1898.

33. Pfeffer MA, Braunwald E, Moyé LA, Basta L, Brown EJ, et al. (1992) Effect of captopril on mortality and morbidity in patients with left ventricular dysfunction after myocardial infarction. Results of the survival and ventricular enlargement trial. The SAVE Investigators. N Engl J Med 327(10): 669-677.

34. Fox KM (2003) Efficacy of perindopril in reduction of cardiovascular events among patients with stable coronary artery disease: randomised, double-blind, placebo-controlled, multicentre trial (the EUROPA study). Lancet 362(9386): 782-788.

35. Julius S, Nesbitt SD, Egan BM, Weber MA, Michelson EL, et al. (2006) Feasibility of treating prehypertension with an angiotensinreceptorblocker. N Engl J Med 354(16): 1685-1697.

Your next submission with Juniper Publishers
will reach you the below assets
- Quality Editorial service
- Swift Peer Review
- Reprints availability
- E-prints Service
- Manuscript Podcast for convenient understanding
- Global attainment for your research
- Manuscript accessibility in different formats
( Pdf, E-pub, Full Text, Audio)
- Unceasing customer service
Track the below URL for one-step submission
https://juniperpublishers.com/online-submission.php

